5. Pascale Massin M, PhD. Safty and Efficacy of Ranibizumab in Diabetic Macular Edema Diabetes Care. 2010;33:2399-2405.

6. Chen YP, Wu AL, Chuang $C C$, Chen SN. Factors influencing clinical outcomes in patients with diabetic macular edema treated with intravitreal ranibizumab: comparison between responder and non-responder cases. Sci Rep. 2019;9(1):10952.

7. Campos A. Evaluation of markers of outcome in realworld treatment of diabetic macular edema. Eye and Vision. 2018.

\title{
TÁC DỤNG CỦA PHƯƠNG PHÁP CẤY CHỈ HUYÊTT THÂ̂N DU KẾT HỢP ĐIỆN XUNG TRONG ĐÎ̂̀U TRI ĐAU THẮT LƯNG DO THOÁI HOÁ CộT SỐNG
} Hồ Thị Tâm ${ }^{1}$, Nguyễn Thị Thu Hà ${ }^{2}$

\section{TÓM TẮT}

Mục tiêu: Đánh giá tác dụng của phương pháp cây chỉ huyệt thận du kết hợp điện xung trong điều trị đau thắt lưng do thoái hóa cột sống. Phương pháp: Nghiên cứu lâm sàng mở, tiến cứu, so sánh trước và sau điều trị có đối chứng. 100 bệnh nhân chia thành 2 nhóm: nhóm nghiên cứu dùng cấy chỉ kết hợp điện xung, nhóm chứng dùng điện xung đơn thuần. Kết quả: Sau 30 ngày điêu trị, nhóm nghiên cứu có điểm đau VAS trung bình giảm từ 7,92 $\pm 1,44$ (điểm) xuống $0,18 \pm 0,78$ (điểm), thấp hơn nhóm chứng có ý nghĩa thống kê $(p<0,05)$. Cải thiện tầm vận động cột sống thắt lưng, nhóm nghiên cứu tốt hơn nhóm chứng với $\mathrm{p}$ $<0,05$. Kết quả điêuu trị chung: Tốt $90 \%$, khá $10 \%$. Kết luận: Cấy chỉ huyệt thận du kết hợp điện xung có hiệu quả tốt trong điều trị đau thắt lưng do thoái hóa cột sống.

Tư khoá: Cây chỉ, điện xung, đau thắt lưng.

\section{SUMMARY}

THE EFFECTS OF KIDNEY SHU ACUPOINT

CATGUT EMBEDDING COMBINED WITH ELECTROTHERAPY IN TREATMENT LOW BACK PAIN DUE TO DEGENERATIVE SPINE

Objectives: Evaluate effects of kidney shu acupoint catgut embedding combined with electrotherapy in treatment low back pain due to degenerative spine. Methods: This is an open clinical trial with comparison before and after treatment's result and compare with control group. 100 patients were divided into two group: the study group used acupoint catgut embedding combined with electrotherapy, the control group used electrotherapy. Results: After 30 days treatment, the VAS score of the study group was decreased from $7.92 \pm 1.44$ (points) to $0.18 \pm 0.78$ (points), lower than that of the control group $(p<0.05)$. Improved the range of lumbar spine, the study group was better than control group $(p<0.05)$. Overall treatment results: $90 \%$ good, $10 \%$ moderate. Conclusion: The combination

\footnotetext{
${ }^{1}$ Bênh viện đa khoa Thành phố Vinh 2 Trường Đai hoc Y Hà Nôi

Chịu trách nhiệm chính: Nguyễn Thị Thu Hà

Email: nguyenthithuha@hmu.edu.vn

Ngày nhận bài: 10.9.2021

Ngày phản biên khoa hoc: 1.11 .2021

Ngày duyệt bài: 12.11.2021
}

of kidney shu acupoint catgut embedding with electrotherapy has good effects in treatment low back pain due to degenerative spine.

Keywords: Acupoint catgut embedding, electrotherapy, low back pain.

\section{I. ĐĂT VẤN ĐỀ}

Đau thắt lưng là một bệnh lý rất thường gặp, có thể xuất hiên ở 70 - 85\% dân số vào một thời điểm trong cuộc đời. Tại Mỹ, đây là nguyên nhân hàng đâu gây hạn chế vận động của phụ nữ dưới tuổi 45, là lý do đứng thứ 2 khiến bệnh nhân phải đi khám bênh [3], [7]. Thoái hóa côtt sống (THCS) là nguyển nhân phổ biến nhất gẩy đau thắt lưng.

Trong điều trị đau thắt lưng do THCS bằng $Y$ học hiện đại, điều trị nội khoa là phương pháp hiệu quả, được ưu tiên lựa chọn hàng đầu. Tuy nhiên những thuốc giảm đau chống viêm có khá nhiêuu tác dụng phụ, đặc biệt khi sử dụng kéo dài. Phồi chức năng cũng có nhiêu phương pháp điều trị bệnh: nhiệt trị liệu, từ trường, sóng ngắn, điên xung, siểu âm dẫn thuốc... Điện xung là một phương pháp điều trị bằng các xung điện có tần số thấp và trung bình, có tác dụng giảm đau và kích thích thân kinh cơ.

Theo $Y$ học cổ truyền (YHCT) đau thắt lưng thuộc phạm vi chứng "Yêu thống" và có nhiều phương pháp điều trị như: châm cứu, xoa bóp bấm huyệt, thuốc đông dược. Cấy chỉ là một phương pháp châm cứu đặc biệt, dễ làm, ít tác dụng phụ, giảm thời gian đi lại cho bệnh nhân, rất phù hợp trong việc điều trị các bênh mạn tính [4]. Thận du là huyệt du của tạng Thận có tác dụng ích thủy, tráng hỏa, điều hòa thận khí, kiện cân cốt, chữa đau lưng, minh mục, thông nhĩ... Lưng là phủ của thân nên những bênh lý đau lưng đều có liên quan đến tạng thận và huyệt Thận du thường được sử dụng trong điêu trị bệnh lý của tạng thận trên lâm sàng [1], [6].

Hiên nay, phương pháp điên xung kết hợp cây chỉ huyệt Thân du trong điều trị đau thắt lưng trên lâm sàng đã mang lại những hiệu quả 
nhất định. Để tìm hiểu thêm và nâng cao hiệu quả điều trị, chúng tôi tiến hành nghiên với mục tiêu: Đánh giá tác dung của phương pháp cây chi huyệt thận du kêt hợp điện xung trong điều trị đau thắt lưng do thoái hóa cột sông.

\section{II. ĐỐI TƯợNG VÀ PHƯƠNG PHÁP NGHIÊN CứU}

2.1. Đối tượng nghiên cứu: 100 bệnh nhân (BN) được chẩn đoán là đau thắt lưng do THCS, điều trị tại khoa YHCT - Bệnh viện Đa khoa Thành phố Vinh từ tháng 08/2020 đến tháng 08/2021.

- Tiêu chuẩn chon BN theo YHHĐ: BN từ 38 tuổi trở lên, được chẩn đoán xác định đau thắt lưng do THCSC, tình nguyện tham gia nghiên cứu.

- Tiêu chuẩn chọn BN theo YHCT: Bệnh nhân chẩn đoán yêu thống thể can thận hư hoặc thể phong hàn thấp kèm can thận hư.

- Tiêu chuẩn loại trừ: Đau thắt lưng kèm theo bệnh nhiễm trùng, nhiễm độc toàn thân, bênh ngoài da vùng thắt lưng (nấm, viêm da cơ địa...), đái tháo đường, viêm cột sống dính khớp, lao cột sống, ung thư nguyên phát, thứ phát, chấn thương gãy đốt sống ; BN có tiền sử dị ứng và dị ứng với chỉ catgut; BN không tuân thủ điều trị.

\subsection{Phương pháp nghiên cứu}

* Thiết kế nghiên cứu: Nghiên cứu được tiến hành theo phương pháp tiến cứu, can thiệp lâm sàng, so sánh trước và sau điêu trị, có đối chứng.

* Cỡ mẫu nghiên cứu: Chọn cõ̃ mẫu chủ đích gồm 100 BN đáp ứng tiêu chuẩn lựa chọn, ghép că̆p tương đồng về tuổi, giới, mức độ bệnh, chia thành 2 nhóm:

- Nhóm nghiên cứu (nhóm NC): 50 BN tiến hành cấy chỉ kết hợp điện xung. Cấy chỉ catgut vào huyệt Thận du, tại 2 thời điểm: lần 1 vào ngày thứ nhất, lần 2 vào ngày thứ 15 của liệu trình điều trị. Điệ̂n xung ngày 1 lần, mỗi lần 20 phút.

- Nhóm chứng: 50 BN tiến hành điện xung ngày 1 lần, mỗi lần 20 phút

* Chỉ tiêu nghiên cứu và phương pháp đánh giá kêt quả:

- Mức độ đau của bệnh nhân theo thang điểm VAS.

Tầm vận động cột sống thắt lưng: Cúi, ngửa, nghiêng, xoay

Bảng 2.1. Đánh giá tâm vận động cột sông thắt lưng

\begin{tabular}{|c|c|c|c|c|c|}
\hline Mức độ & Gấp & Duôii & Nghiêng & Xoay & Điếm \\
\hline Tốt & $\geq 70^{\circ}$ & $\geq 25^{\circ}$ & $\geq 30^{\circ}$ & $\geq 25^{\circ}$ & 1 \\
\hline Khá & $\geq 60^{\circ}$ & $\geq 20^{\circ}$ & $\geq 25^{\circ}$ & $\geq 20^{\circ}$ & 2 \\
\hline Trung & $\geq 40^{\circ}$ & $\geq 15^{\circ}$ & $\geq 20^{\circ}$ & $\geq 15^{\circ}$ & 3 \\
\hline
\end{tabular}

\begin{tabular}{|c|c|c|c|c|c|}
\hline bình & & & & & \\
\hline Kém & $<40^{\circ}$ & $<15^{\circ}$ & $<20^{\circ}$ & $<15^{\circ}$ & 4 \\
\hline
\end{tabular}

- Đánh giá hiệu quả điều trị dựa vào sự giảm của tổng số điểm thay đổi của 4 chỉ số: Mức độ đau VAS, độ giãn CSTL, tầm vận động CSTL, chức năng hoạt động CSTL:

Hiệu quå điều trị $=\frac{\mid \text { Tổng điểm TĐT }- \text { Tổng điểm SĐT } \mid}{\text { Tổng điểm TĐT }} \times 100 \%$

Phân loai hiêuu quả điều trị như sau:

Tốt: $\geq 60 \%$; Khá: $\geq 40 \%$ đến dưới $60 \%$

Trung bình: từ $\geq 20 \%$ đến dưới $40 \%$; Kém: $<20 \%$

Các chỉ tiêu được theo dõi tại thời điểm trước điều trị $\left(D_{0}\right)$, sau điều trị 15 ngày $\left(D_{15}\right)$ và sau điêuu trị 30 ngày $\left(D_{30}\right)$.

2.4. Thời gian và địa điểm nghiên cứu: Nghiên cứu được tiến hành tại khoa YHCT - Bênh viện Đa khoa Thành phố Vinh từ tháng 08/2020 đển tháng 08/2021.

2.5. Phương pháp xử lý số liệu: Số liệu thu thập được xử lý theo thuật toán thống kê Y sinh học, sử dụng phần mềm SPSS 25.0.

2.6. Đạo đức nghiên cứu: Bệnh nhân đều tự nguyên tham gia nghiên cứu. Nghiên cứu chì nhằm bảo vê và nâng cao sức khỏe cho bênh nhân. Các thông tin của bệnh nhân đều được bảo mật và chỉ phục vụ cho mục tiêu nghiên cứu.

\section{KẾT QUẢ NGHIÊN CỨU}

\section{VAS}

\subsection{Hiệu quả giảm đau theo thang điểm}

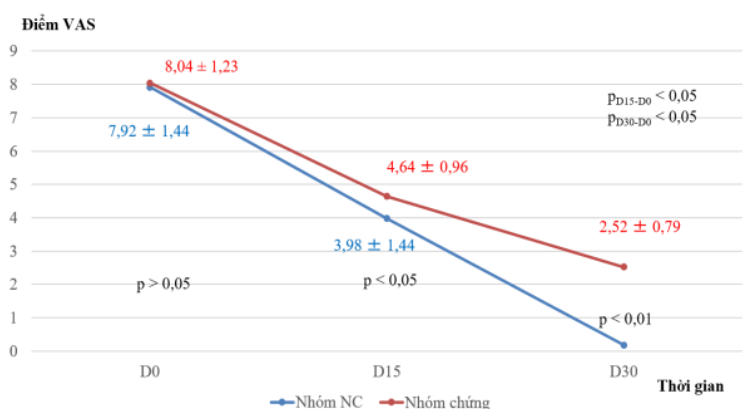

Biểu đồ 3.1. Hiệu quả giảm đau theo thang điểm VAS

Nhân xét: Sau điều trị điểm VAS trung bình ở cả 2 nhóm đều giảm có ý nghĩa thống kê so với trước điều trị $(p<0,05)$. Điểm VAS trung bình của nhóm nghiên cứu giảm nhiều hơn nhóm chứng. Sự khác biệt giữa hai nhóm có ý nghĩa thống kê với $p<0,05$ sau 15 ngày và $p<0,01$ sau 30 ngày điều trị.

3.2. Hiệu quả cải thiện tâm vận động cột sống thắt lưng. 
Bảng 3.1. Sự thay đổi tầm vận động cột sông thắt lưng trước và sau điều trị

\begin{tabular}{|c|c|c|c|c|c|c|}
\hline \multirow{2}{*}{ Mức đô han chế Nhóm } & \multicolumn{2}{|c|}{ Nhóm NC $(n=50)$} & \multicolumn{2}{|c|}{ Nhóm chứng $(n=50)$} & \multicolumn{2}{|c|}{ PNC-C } \\
\hline & Do n (\%) & D30 n (\%) & Don (\%) & D30 n (\%) & DO & D30 \\
\hline Tốt & 0 & $47(94)$ & 0 & 0 & \multirow{4}{*}{$>0,05$} & \multirow{4}{*}{$<0,05$} \\
\hline Khá & 0 & $3(6)$ & 0 & $48(96)$ & & \\
\hline Trung bình & $5(10)$ & 0 & $5(10)$ & $2(4)$ & & \\
\hline Kém & $45(90)$ & 0 & $45(90)$ & 0 & & \\
\hline PD30-D0 & \multicolumn{2}{|c|}{$<0,05$} & \multicolumn{2}{|c|}{$<0,05$} & & \\
\hline
\end{tabular}

Nhận xét: Sau 30 ngày điều trị, ở cả 2 nhóm đều cải thiện tầm vận động CSTL với $p<0,05$. Nhóm nghiên cứu cải thiện tốt hơn nhóm chứng với sự khác biệt có ý nghĩa thống kê $(p<0,05)$.

\subsection{Kết quả điều trị chung}

Bảng 3.2. So sánh hiệu quả điều trị chung

\begin{tabular}{|c|c|c|c|c|c|c|c|c|}
\hline \multirow{3}{*}{ Kết quả Nhóm } & \multicolumn{4}{|c|}{ Nhóm NC } & \multicolumn{4}{|c|}{ Nhóm chứng } \\
\hline & \multicolumn{2}{|r|}{$D_{15}$} & \multicolumn{2}{|r|}{$D_{30}$} & \multicolumn{2}{|r|}{$D_{15}$} & \multicolumn{2}{|c|}{$D_{30}$} \\
\hline & $\mathbf{n}$ & Tỷ lệ \% & $\mathbf{n}$ & Tỷ lệ \% & $\mathbf{n}$ & Tỷ lệ \% & $\mathbf{n}$ & Tỷ lệ \% \\
\hline Tốt & 0 & 0,0 & 45 & 90,0 & 0 & 0,0 & 2 & 4,0 \\
\hline Khá & 19 & 38,0 & 5 & 10,0 & 1 & 2,0 & 46 & 92,0 \\
\hline Trung bình & 31 & 62,0 & 0 & 0,0 & 48 & 96,0 & 2 & 4,0 \\
\hline Kém & 0 & 0,0 & 0 & 0,0 & 1 & 2,0 & 0 & 0 \\
\hline PD15-D30 & & & & & & & & \\
\hline $\mathrm{PD}_{\mathrm{D} 5(\mathrm{NC}-\mathrm{C}),} \mathrm{P}_{\mathrm{D} 30(\mathrm{NC}-\mathrm{C})}$ & & & & & & & & \\
\hline
\end{tabular}

Nhận xét: Sau 15 ngày điều trị, nhóm nghiên cứu đạt kết quả khá $38 \%$, trung bình $62 \%$; nhóm chứng có kết quả khá $2 \%$, trung bình $96 \%$. Sau 30 ngày điêu trị nhóm nghiên cứu có $90 \%$ BN đạt kết quả tốt, $10 \%$ đạt kết quả khá. Tỷ lệ tốt và khá ở nhóm chứng thấp hơn là $4 \%$ và $92 \%, 4 \%$ kết quả trung bình. Kết quả điều trị của nhóm nghiên cứu tốt hơn nhóm chứng tại cả hai thời điểm sau 15 ngày và sau 30 ngày điểu trị với sự khác biệt có ý nghĩa thống kê $(p<0,05)$

\section{BÀN LUẬN}

Sau điều trị điểm VAS trung bình ở cả 2 nhóm đều giảm có ý nghĩa thống kê so với trước điêu trị $(p<0,05)$. Điểm VAS trung bình của nhóm nghiên cứu giảm từ 7,92 $\pm 1,44$ (điểm) xuống $0,18 \pm 0,78$ điểm, nhiêu hơn so với nhóm chứng từ 8,04 $\pm 1,23$ (điểm) xuống 2,52 $\pm 0,79$ (điểm). Sự khác biệt giữa hai nhóm có ý nghĩa thống kê với $p<0,05$. Như vậy cả điện điện xung và cấy chỉ đều có tác dụng giảm đau trong điêu trị đau thắt lưng do THCS. Tác dụng giảm đau của nhóm sử dụng điện xung kết hợp với cấy chỉ tốt hơn nhóm điện xung đơn thuần.

Điện xung là phương pháp sử dụng dòng điện do nhiều xung điện liên tiếp tạo nên, các xung điện này không liên tục mà xen kẽ bởi các khoảng nghỉ không có dòng điện. Kích thích thần kinh cảm giác bằng điện qua da có tác dụng giảm đau theo cơ chế kiểm soát cổng của Melzack và Wall. Theo đó các tín hiệu đau theo các sợi dẫn đau $A \delta$ và $C$ đường kính nhỏ tốc độ chậm bị chặn tại tủy gai nên ít tới các trung khu thần kinh cao hơn, do đó cảm giác đau giảm hoặc mất hẳn [2], [8]. Điện xung có tác dụng tăng tuần hoàn máu, giãn mạch, giảm co thắt, giảm đau.

Cấy chỉ là một phương pháp châm cứu đặc biệt, là một bước tiến của kỹ thuật châm cứu. Bẳng việc đưa chỉ tự tiêu vào huyệt của hệ kinh lạc nhằm duy trì sự kích thích lâu dài qua đó tạo nên tác dụng trị liệu. Cây chỉ làm tăng sự đồng hóa, giảm dị hóa của cơ, tân sinh huyết quản cải thiện tuần hoàn vùng cơ. Theo YHCT cấy chỉ là điều hòa khí huyết, nhằm lập lại cân bằng âm dương, kích thích vào huyệt tạo tác dụng phá ứ trệ, thông kinh lạc giúp lưu thông khí huyết. Khí hòa thì huyết hòa, khí huyết điều hòa, kinh lạc vận chuyển lưu lợi thông suốt thì hết đau " thông bất thống" [4], [5]]. Trong nghiên cứu này, chúng tôi sử dụng huyệt Thận du là huyệt bối du của tạng Thận có tác dụng ích thủy, tráng hỏa, điều hòa thận khí, kiện cân cốt, chữa đau lưng, minh mục, thông nhî̃... Lưng là phủ của thận nên những bệnh lý đau lưng đều có liên quan đến tạng thận và huyệt Thận du thường được sử dụng trong điều trị bệnh lý của tạng thận trên lâm sàng [1], [6]. Sự hiệp đồng tác dụng của điện xung, cấy chỉ huyệt Thận du làm cho tác dụng giảm đau tăng lên và phát huy sớm, vì vậy mà sau 30 ngày điêu trị mức độ đau của BN ở nhóm nghiên cứu được cải thiện tốt hơn và có ý nghĩa thống kê so với nhóm chứng $(p<0,05)$.

Đau vùng thắt lưng do thoái hóa cột sống làm co rút các cơ cạnh sống, co rút các tổ chức liên 
kết bao gồm gân cớ, dây chằng, bao khớp, do đó mà gây ra hạn chế tầm vận động CSTL. Cấy chỉ huyệt Thận du kết hợp với điện xung làm giảm đau, giảm co cứng cớ, tăng khả năng vận động, tăng tính linh hoạt của cột sống. Vì vậy sau 30 ngày điều trị, ở cả 2 nhóm đều cải thiện tầm vận động CSTL với $p<0,05$. Nhóm nghiên cứu cải thiện tốt hơn nhóm chứng với sự khác biệt có ý nghĩa thống kê $(p<0,05)$.

Đánh giá kết quả điều trị không dựa vào một khía cạnh mà từ nhiều góc độ khác nhau như kết quả giảm đau, kết quả cải thiện tầm vận động CSTL... mà bao gồm cải thiện chất lượng cuộc sống của người bệnh. Chúng tôi đánh giá trển các chỉ số: mức độ đau, độ giãn, tầm vận động, chức năng hoạt động của CSTL.

Kết quả nghiên cứu cho thấy sau 15 ngày điều trị, nhóm nghiên cứu đạt kết quả khá 38\%, trung bình 62\%; nhóm chứng có kết quả khá $2 \%$, trung bình $96 \%$. Sau 30 ngày điều trị nhóm nghiên cứu có $90 \%$ BN đạt kết quả tốt, $10 \%$ đạt kết quả khá. Tỷ lệ tốt và khá ở nhóm chứng thẩp hơn là $4 \%$ và $92 \%, 4 \%$ kết quả trung bình. Kết quả điều trị của nhóm nghiên cứu tốt hơn nhóm chứng tại cả hai thời điểm sau 15 ngày và sau 30 ngày điều trị với sự khác biệt có ý nghĩa thống kê $(p<0,05)$. Nhóm nghiên cứu có tác dụng giảm đau, cải thiện tầm vận động và chức năng hoạt động cột sống thắt lưng tốt hơn nhóm chứng nên kết quả điều trị chung tốt hơn.

\section{KẾT LUẬN}

Cấy chỉ huyệt thận du kết hợp điện xung có hiệu quả tốt trong điều trị đau thắt lưng do thoái hóa cột sống.

\section{TÀI LIÊU THAM KHẢO}

1. Trân Thúy, Phạm Duy Nhạc, Hoàng Bảo Châu (2011). Bài giảng $Y$ học cổ truyền. (2). NXB Y học Hà Nội,

2. Nguyển Thị Tú, Đỗ Kiên Cường (2012). Điện trị liệu: Nguyên lý - Thiết bị - Thực hành. Đại học quốc gia TP Hồ Chí Minh.

3. Nguyến Thi Ngoc Lan (2016). Bênh học cơ xương khớp nội khoa. NXB Giáo dục; 89-92.

4. Lê Thúy Oanh (2010). Cấy Chỉ. Nhà xuất bản $Y$ hoc; $39-45$

5. Học viện y học cổ truyên Trung Quốc. Châm cứu hoc Trung Quốc. Nhà xuất bản Y hoc

6. Ngiêm Hữu Thành (2007). Thoái hóa khớp theo $Y$ hoc cổ truyền. Nhà xuất bán $Y$ hoc; 11-20.

7. Vũ Thị Thanh Thủy (2012). Chẩn đoán và điều trị những bệnh cơ xương khớp thường gặp. Nhà xuất bản Y hoc, Hà Nôi; 2012:76-82.

8. PT MHC MD (2012). Physical Agents in Rehabilitation: From Research to Practice. Elsevier Health Sciences.

\section{RỐI LOAN CHUYỂN HÓA SẮT Ở BÊ̂NH NHÂN NHIỄM HELICOBACTER PYLORI}

\section{TÓM TẮT}

Đặt vấn đề: Tỉ lệ bệnh nhân nhiễm Helicobacter pylori có sự rối loạn chuyển hóa về sắt huyết thanh đặc biệt là thiếu sắt chiếm tỉ lệ trên $35 \%{ }^{[5]}$. Mục tiêu: xác định sư tương quan giữa tình trang thiểu sắt ở bệnh nhân được chẩn đoán nhiễm Helicobacter pylori. Phương pháp: Nghiên cứu bệnh chứng. Kết quả: Sắt huyết thanh ở nhóm bệnh nhân dương tính với H.pylori thấp hơn so với nhóm âm tính $(59,4 \pm 3,92$ $\mu \mathrm{g} / \mathrm{dL}$ và $82,3 \pm 3,04 \mu \mathrm{g} / \mathrm{dL}, \mathrm{p}<0,001$ ). Những bệnh nhân dương tính với HP có tî lệ giảm sắt huyết thanh cao gấp 10,6 lần $(\mathrm{OR}=10,6$; KTC95\% 5,3 - 22,3) so với những người âm tính với $H P$, với $p<0,001$. Nông độ sắt huyết thanh có mối tương quan với các chỉ số

*Đại họ Y Dược TP. HCM

Chịu trách nhiệm chính: Hà Mạnh Tuấn

Email: hamanhtuan@ump.edu.vn

Ngày nhận bài: 6.9.2021

Ngày phản biện khoa học: 15.10.2021

Ngày duyệt bài: 8.11.2021

\section{Huỳnh Phương Duy ${ }^{1}$, Lâm Vĩnh Niên', Đoàn Thanh Hải ${ }^{1}$, Hà Mạnh Tuấn ${ }^{1}$}

hồng cầu bao gồm $\mathrm{Hb}(r=0,24, p<0,001)$, MCV $(r=0,28, p<0,001), M C H \quad(r=0,21, p<0,001)$. Kết luận: Có mối tương quan giữa tình trạng nhiễm Helicobacter pylori và các rối loạn về chuyển hóa sắt ở bệnh nhân nhiếm HP.

Ti̛ khóa: Thiếu sắt, Helicobacter pylori, mối tương quan.

\section{SUMMARY \\ DISORDER OF IRON METABOLISM IN PATIENTS WITH HELICOBACTER PYLORI INFECTION \\ Background: The percentage of patients have a Iron metabolism disorders with Helicobacter pylori changes about iron serum, specially the ratio of iron is about deficiency $35 \%$. Objective: Determine the correlation between iron deficiency status in patients diagnosed with Helicobacter pylori infection. Methods: case-control study. Results: Serum iron in the group of patients positive for $\mathrm{H}$.pylori is lower than in the negative group $(59,4 \pm 3,92 \mu \mathrm{g} / \mathrm{dL}$ và $82,3 \pm$ $3,04 \mu \mathrm{g} / \mathrm{dL}, \mathrm{p}<0,001)$. HP-positive patients have a 10.6 times higher rate of serum iron reduction $(\mathrm{OR}=$}

